\title{
Iron oxide nanoparticles and induced autophagy in human monocytes
}

This article was published in the following Dove Press journal:

International Journal of Nanomedicine

26 May 2017

Number of times this article has been viewed

\author{
QiHong Wu' \\ RongRong Jin ${ }^{2}$ \\ Ting Feng' \\ $\mathrm{Li} \mathrm{Liu}^{2}$ \\ Li Yang ${ }^{2}$ \\ YuHong $\mathrm{Tao}^{3}$ \\ James M Anderson ${ }^{4,5}$ \\ Hua $\mathrm{Ai}^{2,6}$ \\ Hong $\mathrm{Li}^{1,3}$ \\ 'Key Laboratory of Obstetrics, \\ Gynecology, Pediatric Disease, and \\ Birth Defects, Ministry of Education, \\ West China Second University \\ Hospital, ${ }^{2}$ National Engineering \\ Research Center for Biomaterials, \\ ${ }^{3}$ Department of Pediatrics, West \\ China Second University Hospital, \\ Sichuan University, Chengdu, \\ China; ${ }^{4}$ Department of Biomedical \\ Engineering, ${ }^{5}$ Department of \\ Pathology, Case Western Reserve \\ University, Cleveland, OH, US; \\ ${ }^{6}$ Department of Radiology, West \\ China Hospital, Sichuan University, \\ Chengdu, China
}

\begin{abstract}
Superparamagnetic iron oxide nanoparticles have been widely used in biomedical applications, but understanding of their interactions with the biological immune system is relatively limited. This work is focused on dextran-coated iron oxide nanoparticles and their induced autophagy in human monocytes. We found that these nanoparticles can be taken up by human monocytes, followed by localization within vesicles or free in cytoplasm. Autophagosome formation was observed with increased expression of LC3II protein, the specific marker of autophagy. The autophagy substrate p62 was degraded in a dose-dependent manner, and autophagy was blocked by autophagy (or lysosome) inhibitors alone or along with iron oxide nanoparticles, indicating that autophagosome accumulation was mainly due to autophagy induction, rather than blockade of autophagy flux. Interestingly, iron oxide nanoparticles increased the viability of human monocytes, but the mechanism was not clear. We further found that inhibition of autophagy mostly attenuated the survival of cells, with acceleration of the inflammation induced by these nanoparticles. Taken together, autophagic activation in human monocytes may play a protective role against the cytotoxicity of iron oxide nanoparticles.
\end{abstract}

Keywords: autophagy, cytotoxicity, human monocytes, inflammation, iron oxide nanoparticles

\section{Introduction}

Superparamagnetic iron oxide nanoparticles (SPIONs) have gained extensive attention in biomedicine because of their excellent magnetic properties and low cytotoxicity. ${ }^{1}$ SPIONs are clinically approved as magnetic resonance imaging (MRI) contrast agents, and have also been used in hyperthermia drug delivery. ${ }^{2-4}$ Although SPIONs are being tested in many ongoing clinical trials, some controversial results regarding their cytotoxicity have been reported. ${ }^{5}$ Therefore, a more sensitive indicator of cytotoxicity of SPIONs will provide insight into them and their interactions with cells.

Autophagy is a ubiquitous and highly conserved metabolic process believed to occur in all eukaryotic cells, where aged or injured organelles and cellular excessive proteins are sequestered with double-membrane vesicles and digested by the lysosomal pathway. ${ }^{6}$ Nowadays, autophagy has been implicated in numerous important functions of cells and diseases, such as cellular homeostasis, cell survival and death, neuron degenerative diseases, and cancer. ${ }^{7-9}$ Nanoparticles (NPs) have been reported as a novel class of autophagy inducers. ${ }^{10}$ So far, findings have presented a paradox: some reported that the autophagy induced by NPs could promote cell death, but in other conditions it could be a protective role in response to toxicity caused by NPs. ${ }^{1,11,12}$ To the best of our knowledge, there is no report on autophagy caused by SPIONs in human monocyte cells.

NPs can be recognized and taken up by some immune cells. With monocytes as mediators of adaptive and innate immunity, they can be either developed into various
Correspondence: Hua Ai; Hong $\mathrm{L}$ 29 Wangjiang Road/20 Section 3 South Renmin Road, Chengdu, Sichuan 610064/61004I, China Tel +86 28 854I 399I; 85503602

Fax +86 28 854I 399I; 85502930 Email huaai@scu.edu.cn; Ihong3985@163.com (c) (5) 2017 Wu et al. This work is published and licensed by Dove Medical Press Limited. The full terms of this license are available at https:///www.dovepress.com/terms.php
and incorporate the Creative Commons Attribution - Non Commercial (unported, v3.0) License (http://creativecommons.org/licenses/by-nc/3.0/). By accessing the work you

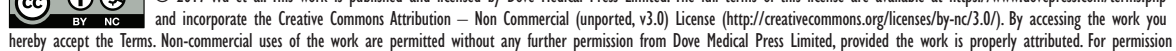
hereby accept the Terms. Non-commercial uses of the work are permitted without any further permission from Dove Medical Press Limited, provided the work is properly attributed. For permission
for commercial use of this work please see pararaphs 42 and 5 of our Terms (hthps//wwww.dovepress com/terms php). 
forms of antigen-presenting cells or involved in tissue homeostasis and various diseases, such as viral and bacterial infections and atherosclerosis. ${ }^{13}$ Moreover, monocytes form the first line of defense in the body's immune system and the door of NPs into the human body. In this study, we assessed the biological behaviors of SPIONs on human monocytes after uptake, concentrating especially on autophagy.

\section{Materials and methods}

Nanoparticle preparation

In this study, dextran-coated SPIONs (Dex-SPIONs) were synthesized following a protocol previously described. ${ }^{14}$ Briefly, a mixture of $2.508 \mathrm{~g}$ Dex T70 (molecular weight 70 kD; Life Science Products, Chestertown, MD, US) and $3.044 \mathrm{~g}$ iron(III) chloride hexahydrate (Aladdin, Shanghai, China) dissolved in $20 \mathrm{~mL}$ of deionized water was put into a three-neck flask equipped with a mechanical stirrer. To this mixture was added a freshly prepared aqueous solution containing $1.27 \mathrm{~g}$ of ferrous chloride tetrahydrate (Aladdin) dissolved in $2 \mathrm{~mL}$ deionized water. While being rapidly stirred, $20 \mathrm{~mL}$ 7.5\% ammonium hydroxide solution was slowly dropped into the mixture under argon protection. Then, the suspension was heated to $75^{\circ} \mathrm{C}$ and maintained at this temperature for 30 minutes while being stirred constantly. The black suspension was cooled and centrifuged at a speed of 1,500 rpm for 15 minutes to separate big particles. The ammonium chloride, excess ammonia, and Dex were removed by dialysis using citrate buffer. Characterization of Dex-SPIONs was performed using transmission electron microscopy (TEM; 2100F; JEOL, Tokyo, Japan). Dynamic light scattering was used to analyze $\zeta$-potential and hydrodynamic size (Zetasizer Nano ZS90; Malvern Instruments, Malvern, UK).

\section{Study subjects and isolation of human monocytes}

Peripheral blood mononuclear cells were prepared from human buffy-coat residues (Chengdu Blood Center, Chengdu, China) by using gradient centrifugation in vitro, and human monocytes $\left(\mathrm{CD} 14^{+}\right.$cells, originating from healthy volunteers and approved by the institutional review board of the West China Second University Hospital of Sichuan University) were purified using magnetic beads according to the manufacturer's recommendations (Miltenyi Biotec, Bergisch Gladbach, Germany). Buffy-coat residues were centrifuged to remove serum, and then the remaining cell sediment was mixed with phosphate-buffered saline (PBS). Diluted buffy-coat residue $(25 \mathrm{~mL})$ was layered onto $20 \mathrm{~mL}$ of Ficoll-Paque Plus, and then centrifugation of the opaque interphase of mononuclear cells at $400 \times g$ for 30 minutes at $16^{\circ} \mathrm{C}$ was conducted to obtain peripheral blood mononuclear cells. By this method, 95\%-98\% viable pure human monocytes (data not shown) were obtained, confirmed by flow cytometry (FACSAria II; BD Biosciences, San Jose, CA, US) and cytospin preparations.

\section{Human monocytes and culture conditions}

After isolation, cells were seeded in 24-well cell-culture plates in Roswell Park Memorial Institute 1640 culture medium (Thermo Fisher Scientific, Waltham, MA, US) supplemented with $10 \%$ heat-inactivated fetal calf serum and antibiotics ( $1 \%$ solution of penicillin $100 \mu \mathrm{g} / \mathrm{mL}$ and streptomycin $100 \mu \mathrm{g} / \mathrm{mL}$; Thermo Fisher Scientific) and incubated at $37^{\circ} \mathrm{C}, 5 \% \mathrm{CO}_{2}$, and $95 \%$ relative humidity for 1 hour (to allow sufficient time for attachment of cells). After cell attachment, the cell-culture medium was aspirated and the cells washed thoroughly with fresh medium to remove unattached cells. The cells were then incubated in fresh prewarmed medium containing the desired doses of Dex-SPIONs for different time intervals (24 or 48 hours).

In some experiments, pretreatment with inhibitors was required. Cells were first incubated with inhibitors containing ex vivo medium and then exposed to fresh Dex-SPION suspensions in medium containing inhibitors. Cells were first treated with the autophagy inhibitor wortmannin and chloroquine (CQ; Sigma-Aldrich, St Louis, MO, US) for 2 hours and then treated with Dex-SPIONs.

\section{Transmission electron microscopy}

Human monocytes $\left(1.2 \times 10^{6}\right.$ cells $\left./ \mathrm{mL}\right)$ were incubated with Dex-SPIONs $(100 \mu \mathrm{g} / \mathrm{mL})$ for 24 hours. Cells were prepared for TEM analysis as previously described. ${ }^{15}$ Briefly, samples were collected and immediately fixed in 3\% glutaraldehyde. Then, samples were rinsed three times with $0.1 \mathrm{M}$ PBS and postfixed with $1 \%$ osmic acid for 2 hours. After being rinsed three times with $0.1 \mathrm{M}$ PBS and serially dehydrated with $50 \%, 70 \%, 80 \%, 90 \%$, and $100 \%$ alcohol and $100 \%$ acetone, the samples were embedded in epoxy resin for making the blocks of cells. Then, ultrathin sections were stained with lead citrate and uranyl acetate and analyzed using routine TEM (H600IV; Hitachi, Tokyo, Japan). Micrographs were prepared and further processed using Adobe Photoshop software.

\section{Ferrozine assay}

Iron concentrations were measured using the ferrozine assay. ${ }^{16}$ After 24 hours' incubation, cells were carefully washed with PBS and resuspended in $100 \mu \mathrm{L}$ of $0.05 \mathrm{~N} \mathrm{NaOH}$. 
After 2 hours' incubation, samples were then mixed with $100 \mu \mathrm{L} 0.01 \mathrm{~N} \mathrm{HCl}$ and $100 \mu \mathrm{L}$ of reagent $\mathrm{A}\left(4.5 \% \mathrm{KMnO}_{4}\right.$ and $1.4 \mathrm{~N} \mathrm{HCl}$ mixed at equal volumes just before use) and incubated at $60^{\circ} \mathrm{C}$ for 2 hours. The reaction mixture was allowed to cool to room temperature before addition of $50 \mu \mathrm{L}$ of reagent $\mathrm{B}$ (6.5 mM ferrozine, $13.1 \mathrm{mM}$ neocuproine, $2 \mathrm{M}$ ascorbic acid, $5 \mathrm{M}$ ammonium acetate). Absorbance of samples was read at $550 \mathrm{~nm}$ using a microplate reader (Bio-Rad Laboratories, Hercules, CA, US) and concentrations calculated using a standard curve prepared with ferrous ethylene diammonium sulfate in $0.01 \mathrm{~N} \mathrm{HCl}$, ranging from 0 to $10 \mu \mathrm{g} \mathrm{Fe} / \mathrm{mL}$.

\section{Western blot analysis}

Human monocytes were seeded in 24-well plates at a density of $1.2 \times 10^{6}$ cells per well in the presence of Dex-SPIONs $(10-100 \mu \mathrm{g} / \mathrm{mL})$ for 24 or 48 hours. Then, the cells were lysed in radioimmunoprecipitation-assay buffer containing a complete protease-inhibitor cocktail. Protein concentrations were determined using a bicinchoninic acid protein-assay kit. An equal amount of protein $(30 \mu \mathrm{g})$ for each sample was subjected to sodium dodecyl sulfate polyacrylamide-gel electrophoresis (15\% or $12 \%$ separation gels) and then transferred to a polyvinylidene fluoride membrane. The membrane was blocked in TBST (Tris-buffered saline, $0.1 \%$ Tween 20) buffer containing 5\% nonfat milk powder, and then incubated with anti-LC3 (1:500; Sigma-Aldrich), antiGAPDH (Cell Signaling Technology, Danvers, MA, US), and anti-p62 (Abcam, Cambridge, UK) overnight at $4^{\circ} \mathrm{C}$. The membranes were then incubated with an appropriate horseradish peroxidase-conjugated secondary antibody for 1 hour at room temperature, then washed and reacted with SuperSignal chemiluminescent substrate. With Adobe Photoshop software, densitometric analysis of Western blot was performed.

\section{Immunofluorescence staining}

Human monocytes were seeded on confocal dishes, and cells were treated with $100 \mu \mathrm{g} / \mathrm{mL}$ Dex-SPIONs for 24 hours. CQ $(30 \mu \mathrm{M})$ was used as a positive control. The cells were fixed with $4 \%$ paraformaldehyde and treated with $0.1 \%$ Triton X-100. Then, cells were processed for immunofluorescence with anti-LC3 (1:200) and then secondary antibody fluorescein isothiocyanate-conjugated goat antirabbit antibody (Thermo Fisher Scientific). Before being analyzed by confocal microscopy, cells were incubated with DAPI (4',6'-diamidino-2-phenylindole; $5 \mu \mathrm{g} / \mathrm{mL}$ ) for 10 minutes. Wavelengths of excitation and emission for DAPI and fluorescein isothiocyanate were $405 / 498 \mathrm{~nm}$ and 488/525 nm, respectively. After being washed with PBS, confocal dishes were examined using laser confocal microscopy with a $40 \times$ or 100× oil-immersion objective lens (FV500; Olympus, Tokyo, Japan) and processed using Olympus FluoView FV1000 software.

\section{CCK-8 assays}

Viability of human monocytes was assessed using CCK-8 (Dojindo, Kumamoto, Japan) following the manufacturer's instructions. Cell viability was expressed as the percentage of viable cells in total cells. Monocytes were seeded in 96-well plates $\left(1.5 \times 10^{5}\right.$ cells per well $)$, and incubated in culture medium containing different concentrations of Dex-SPIONs for 24 or 48 hours. The medium was then discarded and washed with PBS three times. Then, the cells of each well were treated with CCK-8 following the manual and the absorbance was measured at $450 \mathrm{~nm}$ using a microplate reader (Bio-Rad).

\section{Cytokine assays}

At the end of the desired incubation time ( 24 hours), the supernatants were recovered, centrifuged at $10,000 \times g$ for 15 minutes at $4^{\circ} \mathrm{C}$, and stored at $-80^{\circ} \mathrm{C}$ till further analysis. TNF $\alpha$, IL1 $\beta$, and IL6 were evaluated using a commercially available human enzyme-linked immunosorbent assay kit (RayBiotech, Norcross, GA, US).

\section{Phagocytosis}

The phagocytic activity of human monocytes was assessed by measuring the ingestion of fluorescently labeled bacteria (Alexa Fluor 488-Escherichia coli K12; Thermo Fisher Scientific). Prior to the assay, bacteria were opsonized for 1 hour at $37^{\circ} \mathrm{C}$ using a specific opsonizing reagent (polyclonal rabbit anti-E. coli antibody; Thermo Fisher Scientific). Opsonized bacteria were added to monocytes at a ratio of 50:1 and incubated at $37^{\circ} \mathrm{C}$ for up to 4 hours. Cells were washed with PBS to remove uningested bacteria and analyzed immediately. Quantitative analysis of fluorescently labeled bacteria was done using a Multiskan Spectrum (Thermo Fisher Scientific) at excitation and emission wavelengths of 488 and $519 \mathrm{~nm}$, respectively, according to the manufacturer's protocol.

\section{Statistical analysis}

At least three samples were used for each set of experiments. Data are presented as means \pm standard deviation of independent experiments. Unpaired Student's $t$-test was used to compare means of two samples, while one-way analysis of variance was used for group-mean testing. In all cases, $P<0.05$ was considered significant. 


\section{Results}

\section{Physicochemical characterization of Dex-SPIONs}

In this study, Dex was used as coating material for SPIONs because of its good biocompatibility. Dex-SPIONs have been used in clinical applications. ${ }^{17}$ The size of the Dex-SPIONs was determined by TEM and dynamic light scattering. As shown in Figure 1A, Dex-SPIONs had a uniform morphology with some agglomerates, and the diameter was about 5-10 nm. Further study discovered the mean hydrodynamic size was about $60 \mathrm{~nm}$ (Figure 1B). Their $\zeta$-potential was approximately $-11 \mathrm{mV}$ (Figure $1 \mathrm{C}$ ), indicating their negative charge at physiological $\mathrm{pH}$.

\section{Internalization of Dex-SPIONs and autophagy in human monocytes}

Uptake of NPs by cells is an important aspect for cytotoxicity analysis. In Figure 2B, human monocytes treated with Dex-SPIONs exhibited some vacuoles with highly electron-dense Dex-SPIONs and partly degraded organelles compared to the control (Figure 2A). After careful observation of the TEM images, we found that Dex-SPION-treated monocytes presented in the formation of an isolation membrane and a double-membranous phagophore developing into an autophagosome (Figure 2C), indicating the onset of autophagy. Some of the cellular Dex-SPIONs were observed in a double-membrane vesicle, which was emblematic of an autophagosome (Figure 2D). Additionally, Dex-SPIONs were located in either phagosomes or free in the cytoplasm of human monocytes (Figure 2E), and some phagosomes were partly filled, whereas others were filled tightly. Interestingly, there were some bulky vacuoles and numerous pseudopodia of the cell membrane (Figure 2F), suggesting the potential immunoactivation of human monocytes. To understand further the cellular uptake behavior of Dex-SPIONs, we observed that incubation of human monocytes with increased concentrations of Dex-SPIONs resulted in a linear


Figure I Physicochemical characterization of synthesized Dex-SPIONs.

Notes: (A) TEM images of Dex-SPIONs. Magnification $\times 800,000$; (B) hydrodynamic size of Dex-SPIONs; (C) $\zeta$-potential of Dex-SPIONs in I mM KCl solution. Abbreviations: Dex-SPIONs, dextran-coated superparamagnetic iron oxide nanoparticles; TEM, transmission electron microscopy. 

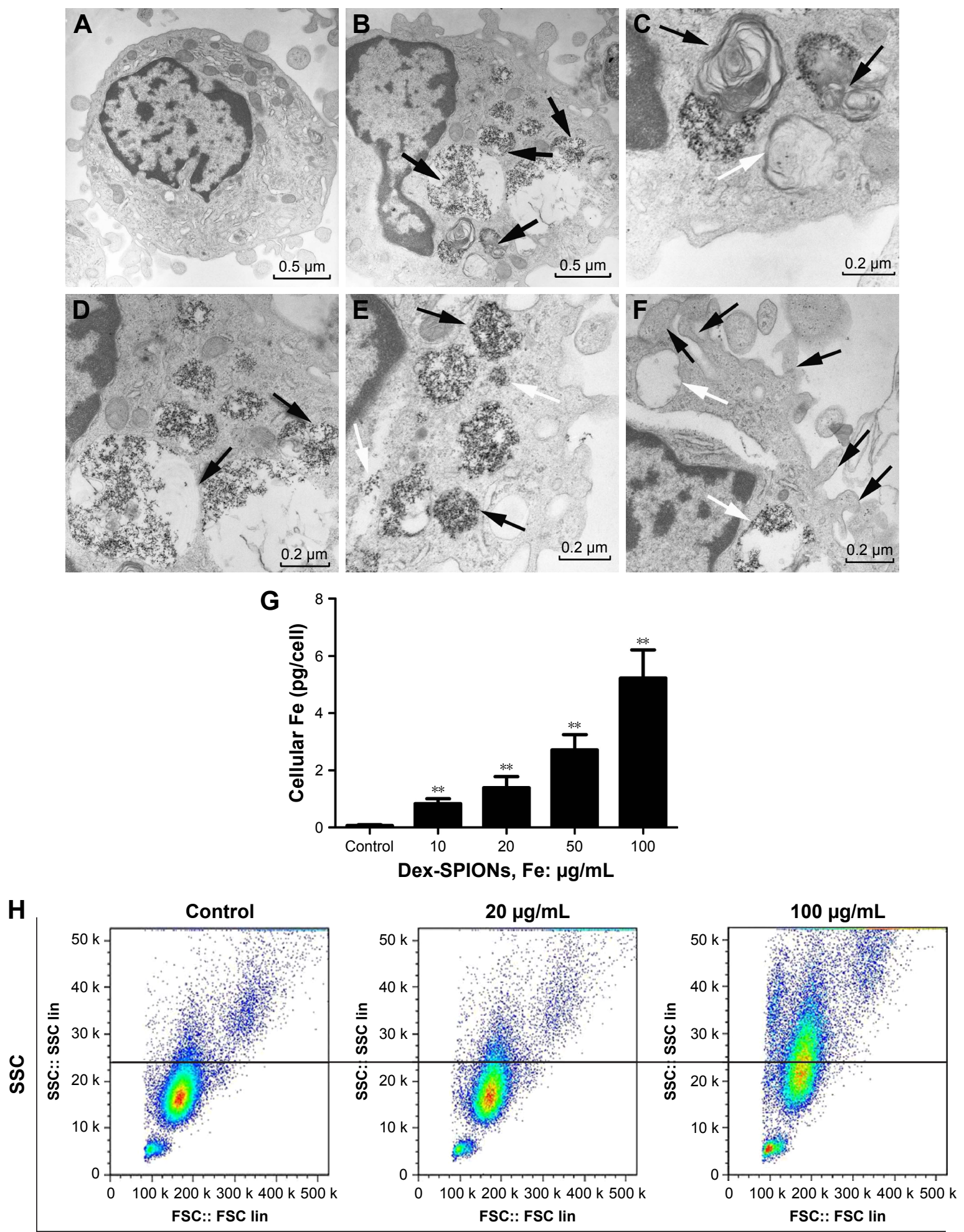

FSC

Figure 2 Cellular uptake of Dex-SPIONs and autophagy in human monocytes.

Notes: Human monocytes were treated with Dex-SPIONs (100 $\mu \mathrm{g} / \mathrm{mL}$ ) or not for 24 hours and processed for TEM analysis. (A) Untreated cells showing typical distribution of organelles. Magnification $\times 8,000$. (B) Human monocytes treated with Dex-SPIONs showing multiple cytoplasmic vacuoles (black arrows). Detailed analysis of monocytes exposed to Dex-SPIONs revealed clear presence of the vacuoles. Magnification $\times 10,000$. (C) An isolation membrane (white arrow) and a doublemembranous phagophore developing into an autophagosome (black arrows). (D) Autophagosomes containing some organelles and electron-dense Dex-SPIONs (black arrows). (E) Dex-SPIONs were either in phagosomes (black arrows) or free in the cytoplasm (white arrows). (F) Some large vacuoles (black arrows) and multiple pseudopodia (white arrows) of the plasma membrane. (G) Concentration-dependent uptake of Dex-SPIONs, as measured by ferrozine assay. Magnification $\times 15,000$. ( $n=3$, $\left.{ }^{*} * P<0.0 I\right)(\mathbf{H})$ Human monocytes were treated with Dex-SPIONs at $20 \mu \mathrm{g} / \mathrm{mL}$ or $100 \mu \mathrm{g} / \mathrm{mL}$ for 24 hours and then detected by flow cytometry.

Abbreviations: Dex-SPIONs, dextran-coated superparamagnetic iron oxide nanoparticles; TEM, transmission electron microscopy; FSC, forward scatter; SSC, side scatter. 
augmentation of intracellular iron content (Figure 2G). Human monocytes treated with Dex-SPIONs $(100 \mu \mathrm{g} / \mathrm{mL})$ for 24 hours contained approximately $5 \mathrm{pg}$ iron/cell, whereas control cells only contained $0.07 \mathrm{pg}$ iron/cell. Moreover, the results of flow-cytometry side scatter also demonstrated that Dex-SPIONs were apparently engulfed by human monocytes (Figure 2H). These results ultimately demonstrated an interaction between Dex-SPIONs and human monocytes that led to autophagy and immunoactivation in human monocytes.

\section{Dex-SPIONs induced autophagosome accumulation in human monocytes}

In Figure $2 \mathrm{C}$ and $\mathrm{D}$, ultrastructural analysis shows that autophagic vacuoles containing Dex-SPIONs and doublemembranous phagophores developed into autophagosomes. To verify further whether Dex-SPIONs were involved in autophagosome formation, we examined a key event in the formation of LC3II, a diagnostic marker of autophagy. ${ }^{18}$ Cytosolic LC3 (LC3I) is converted to the membrane-bound form (LC3II) during the process of autophagy, which gathers on the autophagosome membrane. Therefore, immunoblotting detection of the conversion of LC3I to LC3II and microscopic observation of formation of LC3 puncta are usually used to monitor autophagosome formation. ${ }^{19,20}$ In the present study, immunoblotting suggested that LC3II was increased in a concentration- and time-dependent manner in cells treated with Dex-SPIONs (Figure 3A and B). To visualize whether raised LC3II was gathered on the autophagosome membrane. CQ was used as a positive control which acts as an inhibitor of autophagosome fusion through interfering lysosomes acidification. ${ }^{21}$ The results from immunofluorescence showed that human monocytes treated with Dex-SPIONs revealed a punctate LC3 pattern and quantification of cells with punctate LC3 showed an approximate fivefold increase after Dex-SPION treatment (Figure 3C). In addition, Dex itself did not induce autophagy of human monocytes (Figure 3D). These results demonstrated significant autophagosome accumulation in human monocytes after Dex-SPION uptake.

\section{Autophagy induced by Dex-SPIONs was blocked by inhibitors of autophagy or lysosomes}

Autophagosome accumulation may be a result of autophagy induction or a blockade of autophagic flux. "Autophagic flux" assays can contribute to discrimination of the two possibilities, ${ }^{22}$ exploring the actual autophagy mechanism of Dex-SPIONs in human monocytes. Firstly, we investigated the expression of autophagic substrate p62 in Dex-SPION-treated cells. P62 is selectively entered into autophagosomes and adequately degraded by autophagy. ${ }^{23}$ As shown in Figure 4A, the p62 level was decreased in a concentration-dependent manner, indicating possible induction of autophagy. To further confirm Dex-SPION-induced autophagy, monocytes were treated with Dex-SPIONs alone or along with the autophagy inhibitor wortmannin ${ }^{24}$ or CQ. If the expression of LC3II further advances in the presence of a lysosomal inhibitor, it suggests an increase in autophagic flux. If the LC3II amount were to remain unaltered, it is possible that the autophagosome accumulation is owing to the blockade of autophagy flux. ${ }^{18}$ As shown in Figure 4B-D, cells cotreated with Dex-SPIONs showed higher increase in LC3II transformation than cells treated with CQ alone, and the change in LC3II by Dex-SPIONs vanished after wortmannin exposure. Upon these observations, we considered that autophagosome accumulation by Dex-SPIONs was via autophagy induction, but not blockade of autophagic flux. In addition, PI3K signaling is a pivotal player in regulating autophagy occurrence, and suppression of PI3K activity will weaken autophagy. ${ }^{25}$ In our study, immunoblotting results displayed that the enhancement of LC3II by Dex-SPIONs was reduced by wortmannin. Similarly, confocal microscopy revealed that Dex-SPIONs obviously advanced LC3 punctate structure, but was able to be blocked by wortmannin. Therefore, we surmised that the PI3K signaling might be involved in Dex-SPION-induced autophagy.

\section{Inhibition of autophagy attenuated Dex-SPION-increased survival of human monocytes}

In order to survey the acute toxicity of Dex-SPIONs to human monocytes, which were incubated with Dex-SPIONs $(10-100 \mu \mathrm{g} / \mathrm{mL})$, cell viability was analyzed by CCK-8 assays after 24 and 48 hours. In general, monocytes revealed a decrease in numbers over 20 hours. As such, we normalized the results to the control cells (considered to be 100\%). After 24 hours, there were no apparent signs of cytotoxicity observed by light microscopy (Figure 5A). Similarly, we found that Dex-SPIONs did not affect the viability of human monocytes compared to the control (Figure 5B). Interestingly, monocytes showed a significant increase in percentage of viable cells after a 48-hour exposure to Dex-SPIONs (Figure 5C). It is not known if the Dex-SPION-induced autophagy is important for the survival of human monocytes. We examined the viability of human monocytes with and without wortmannin after 48 hours. Viability of Dex-SPION-treated 
A

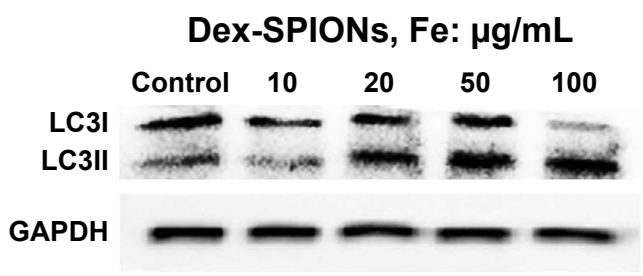

B

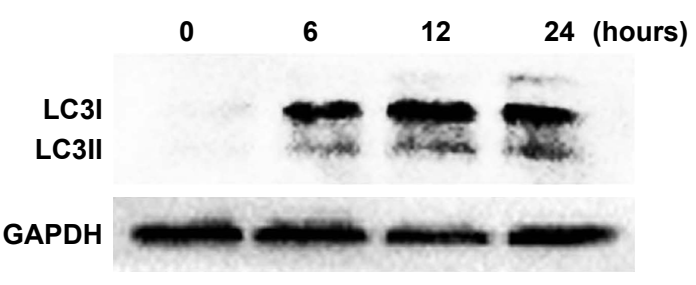

C
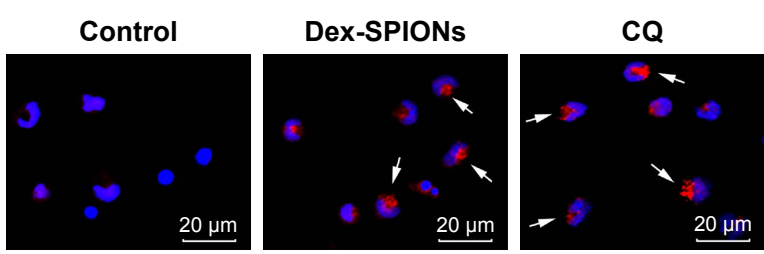

D

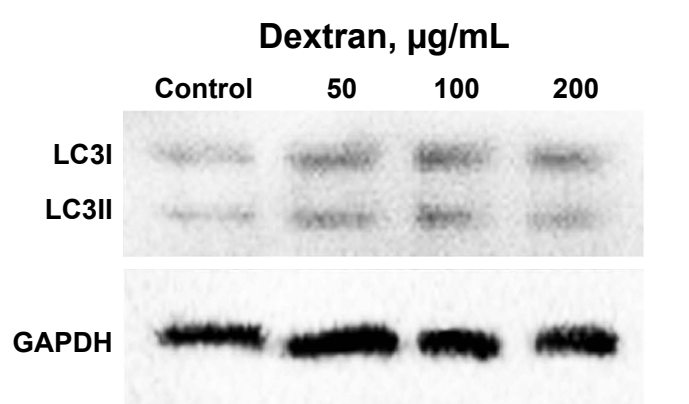

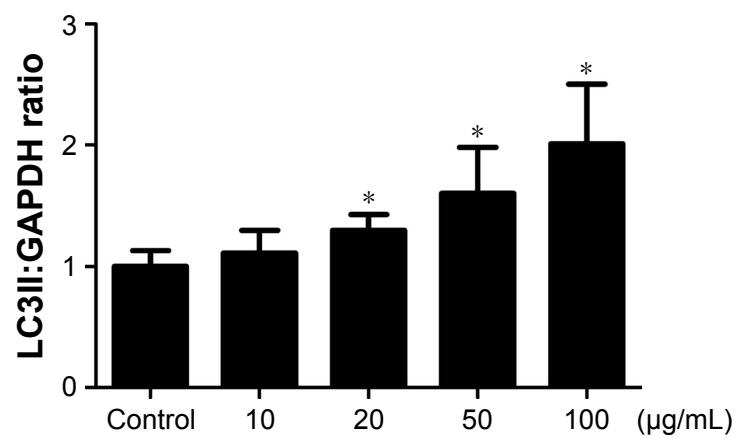
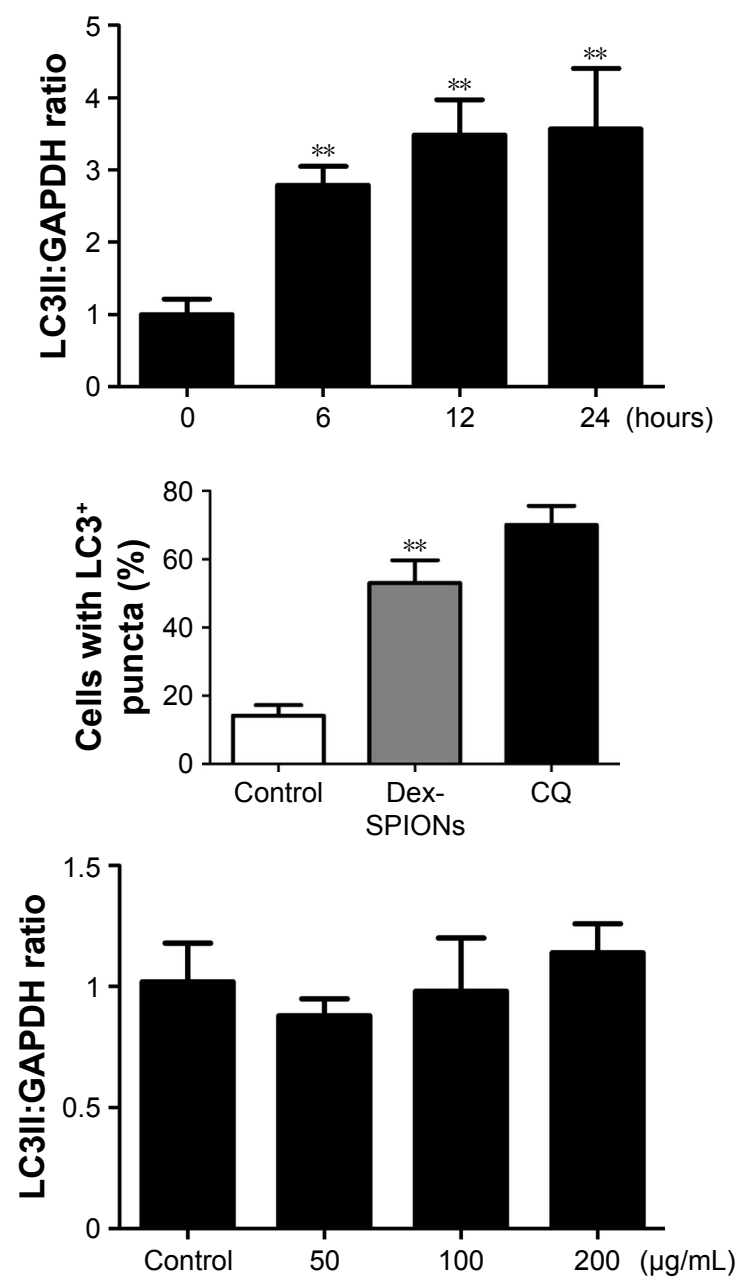

Figure 3 Dex-SPIONs induced autophagosome accumulation in human monocytes.

Notes: $* P<0.05 ; * * P<0.01 ; n=3$. (A) Western blot analysis of LC3 in human monocytes after treatment with various concentrations (I0-100 $\mu g / m L)$ of Dex-SPIONs for 24 hours. (B) Western blot detected LC3 in human monocytes after treatment with Dex-SPIONs ( $100 \mu g / \mathrm{mL})$ at the times indicated. (C) Human monocytes treated or not with Dex-SPIONs (100 $\mu \mathrm{g} / \mathrm{mL})$ for 24 hours, stained with anti-LC3, DAPI (blue), and Alexa Fluor 568 goat antimouse IgG (red), then processed for confocal microscopy. $\mathrm{CQ}(30 \mu \mathrm{M})$ was used as a positive control. Quantitation of the percentage of cells with $\mathrm{LC} 3^{+}$puncta (white arrows). Scale bars $20 \mu \mathrm{m}$. Magnification $\times 60$. (D) Western blot analysis of LC3 in human monocytes after treatment with various concentrations of dextran for 24 hours.

Abbreviations: Dex-SPIONs, dextran-coated superparamagnetic iron oxide nanoparticles; DAPI, 4',6-diamidino-2-phenylindole; CQ, chloroquine.

cells was significantly reduced after wortmannin treatment (Figure 5D). At the same time, immunoblotting results revealed markedly decreased levels of LC3II. These results suggested that autophagy contributed to the improved cellsurvival response to Dex-SPIONs.

\section{Dex-SPIONs induced inflammation of human monocytes}

In Figure 2F, we observed some bulky vacuoles and numerous pseudopodia in the treated cell membrane, suggesting the potential immunoactivation of human monocytes. 
A

Dex-SPIONs, Fe: $\mu \mathrm{g} / \mathrm{mL}$

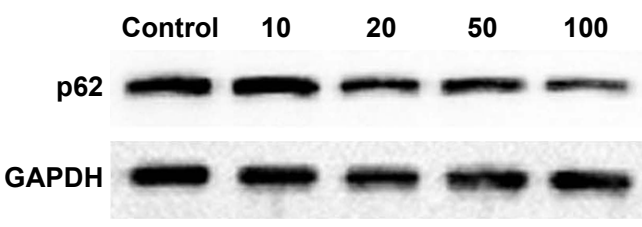

B

C

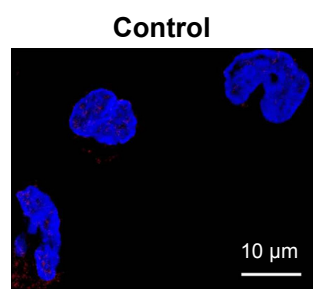

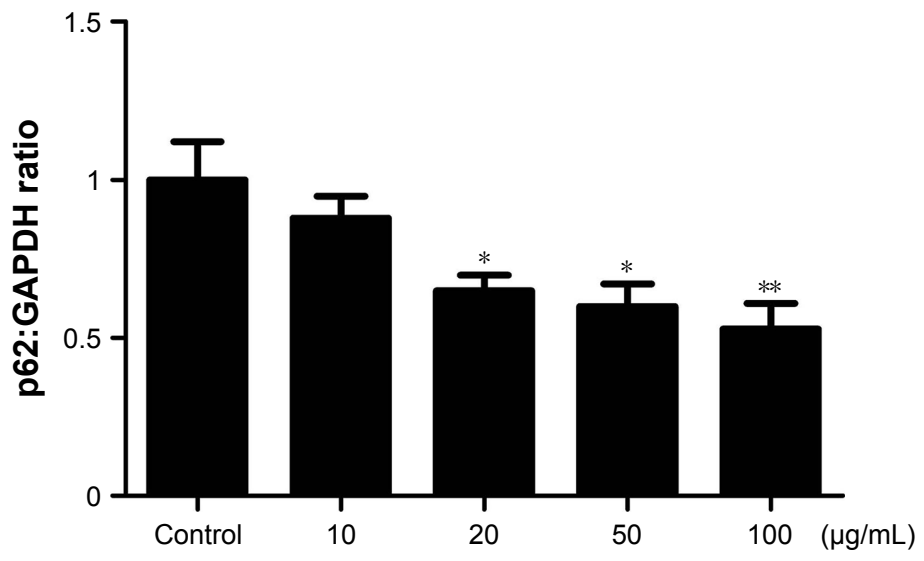

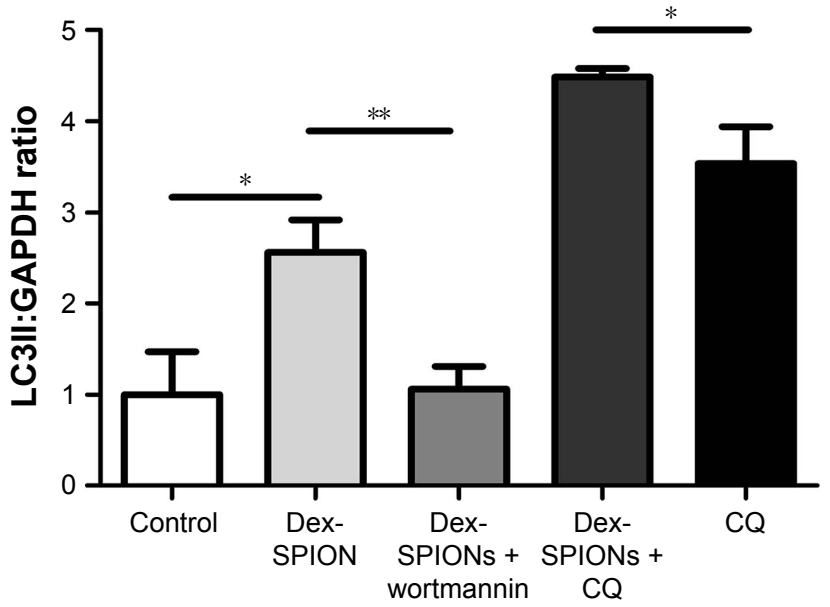

Dex-SPIONs + wortmannin
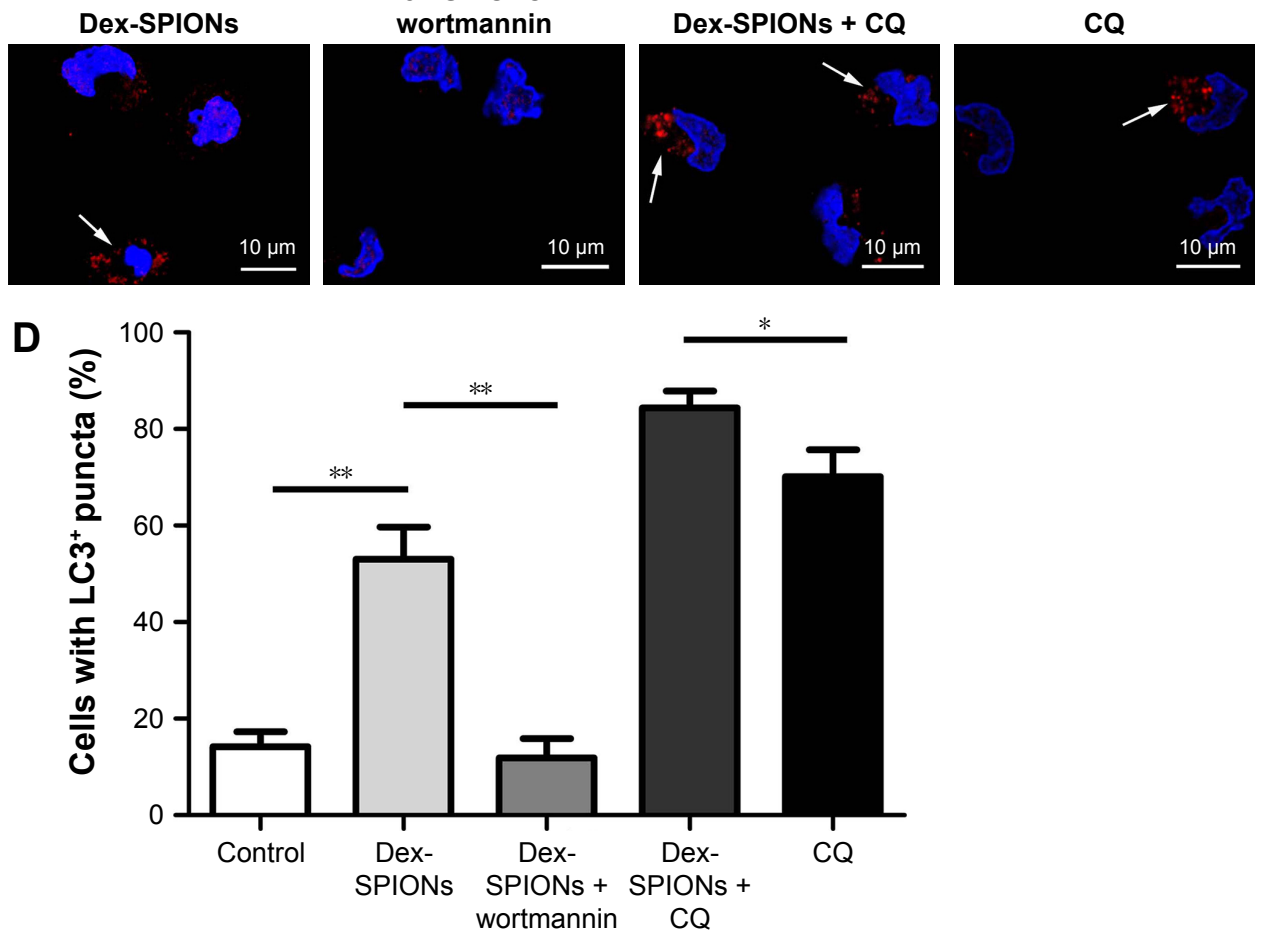

Figure 4 P62 was reduced by autophagy in Dex-SPION-treated human monocytes, and the autophagy was abrogated by autophagy inhibitors

Notes: $* P<0.05 ; * * P<0.01 ; n=3$. (A) Western blot analysis of $p 62$ in human monocytes treated with various concentrations of Dex-SPIONs for 24 hours. (B) Western blot analysis of LC3 in human monocytes incubated with $100 \mu \mathrm{g} / \mathrm{mL}$ Dex-SPIONs for 24 hours. Wortmannin (50 nM) or CQ was added to the cells for 2 hours prior to DexSPION exposure. (C) Confocal microscopy analyzed the LC3 puncta of monocytes. Wortmannin or CQ was added to the cells for 2 hours prior to Dex-SPIONs (I00 $\mu$ g/mL) exposure. Scale bars $10 \mu \mathrm{m}$. Magnification $\times 100$. (D) Quantitation of percentage of cells with $\mathrm{LC}^{+}$puncta (white arrows). Abbreviations: Dex-SPIONs, dextran coated superparamagnetic iron oxide nanoparticles; CQ, chloroquine. 
A

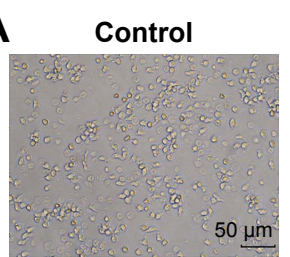

B

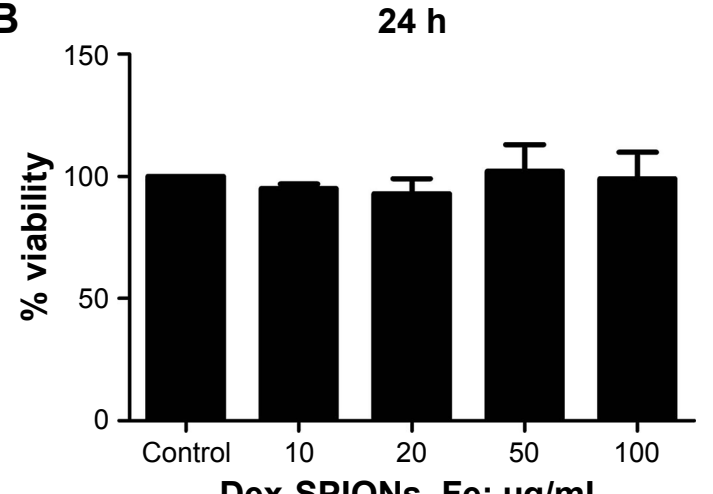

Dex-SPIONs, Fe: $\mu \mathrm{g} / \mathrm{mL}$

D

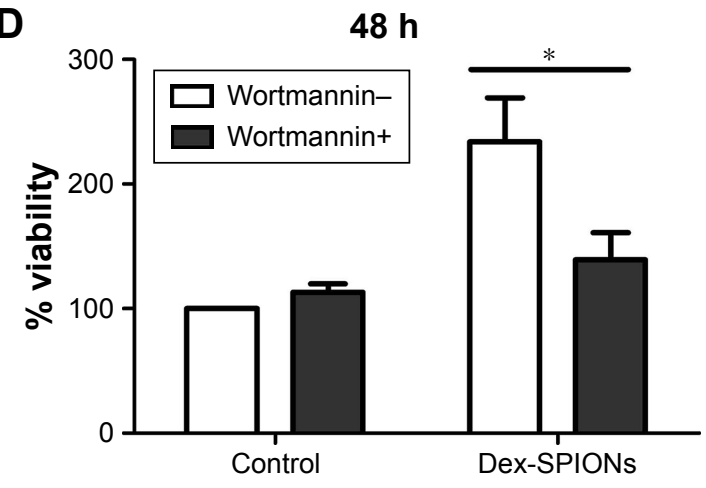

20

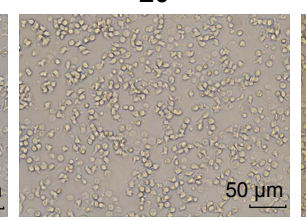

C

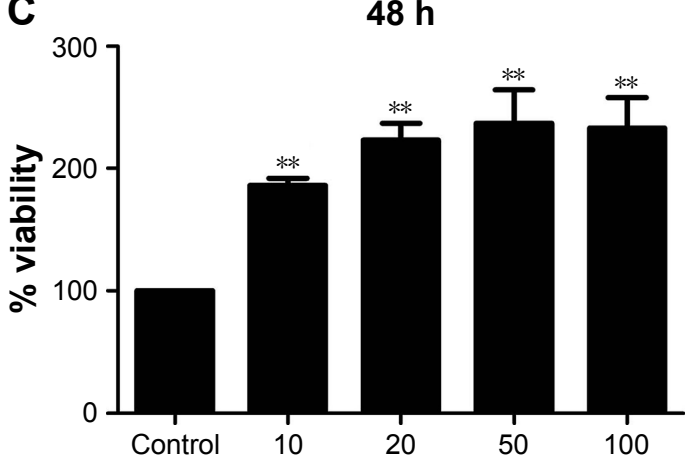

Dex-SPIONs, Fe: $\mu \mathrm{g} / \mathrm{mL}$

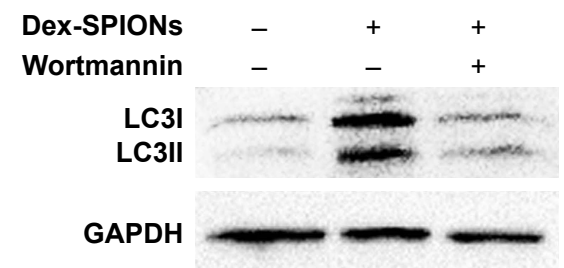

Figure 5 Short-term cytotoxicity of Dex-SPIONs to human monocytes.

Notes: $* P<0.05 ; * *<<0.01 ; n=3$. (A) Human monocytes were observed by phase-contrast microscopy after 24 hours. Scale bars $50 \mu$ m. Magnification $\times 20$. (B, C) Viability of human monocytes treated with Dex-SPIONs $(10-100 \mu \mathrm{g} / \mathrm{mL})$ for 24 or 48 hours. (D) Cell viability was analyzed by CCK-8 and LC3 measured at 48 hours. Wortmannin $(50 \mathrm{nM})$ was added to the cells for 2 hours prior to Dex-SPION treatment.

Abbreviations: CCK-8, cell counting kit; Dex-SPIONs, dextran coated superparamagnetic iron oxide nanoparticles.

To examine further whether Dex-SPIONs activated human monocytes, proinflammatory factors were monitored as indicators of an inflammatory response after cells were treated with Dex-SPIONs for 24 hours. The level of TNF $\alpha$ was markedly elevated in Dex-SPION (50, $100 \mu \mathrm{g} / \mathrm{mL})$ treated cells compared to the control group (Figure 6A). In addition, a similar pattern was observed for IL $1 \beta$ production (Figure 6B). IL6 also showed a similar trend (Figure 6C). Our results showed that Dex-SPIONs caused inflammation of human monocytes through increasing the levels of proinflammatory cytokines.

\section{Suppression of autophagy led to increased inflammation of human monocytes}

To explore further the role of autophagy in Dex-SPIONinduced human monocyte activation, we investigated whether suppression of autophagy had an impact on Dex-SPION-caused inflammation. We pretreated cells with wortmannin, a well known pharmacological inhibitor of the autophagic pathway. ${ }^{26}$ Our results showed that the group treated with wortmannin had elevated levels of TNF $\alpha$, IL1 $\beta$, and IL6 compared to the untreated group (Figure 7A-C). Similarly, the autophagy induced by Dex-SPIONs was also abrogated by wortmannin (Figure 7D). These data indicated that autophagy might be involved in the production of proinflammatory factors, and develop a protection role in resisting the inflammation induced by Dex-SPIONs in human monocytes.

\section{Effects of Dex-SPIONs on human monocyte phagocytosis}

The ability of phagocytosis of human monocytes was studied after the uptake of Dex-SPIONs. The effect of Dex-SPIONs 

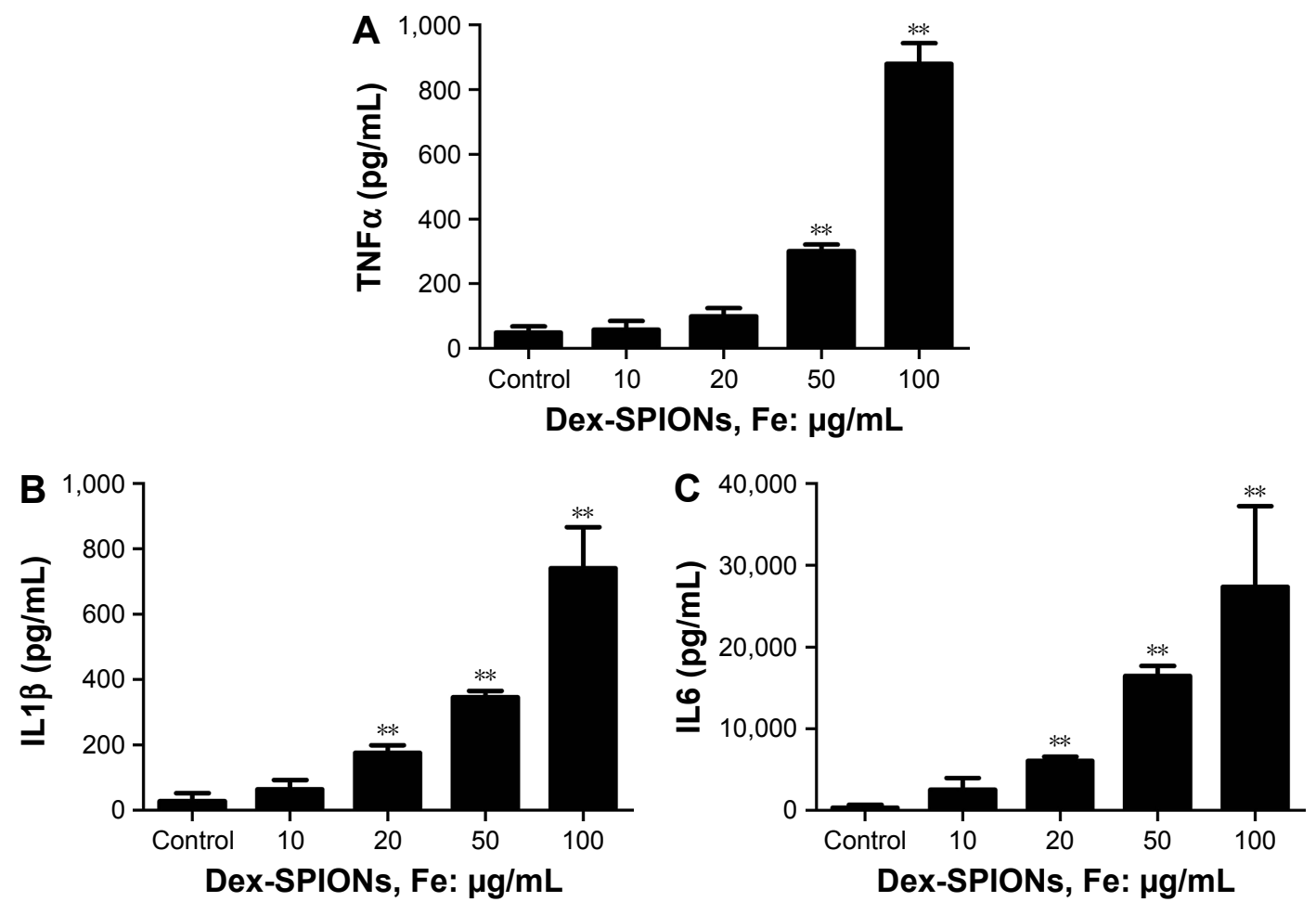

Figure 6 Dex-SPIONs induced inflammation of human monocytes.

Notes: $* * P<0.01 ; n=3$. Cells were treated with or without Dex-SPIONs (I0-100 $\mu \mathrm{g} / \mathrm{mL})$ for 24 hours. (A) TNF $\alpha$ levels; (B) ILI $\beta$ levels; (C) IL6 levels. Abbreviation: Dex-SPIONs, dextran coated superparamagnetic iron oxide nanoparticles.
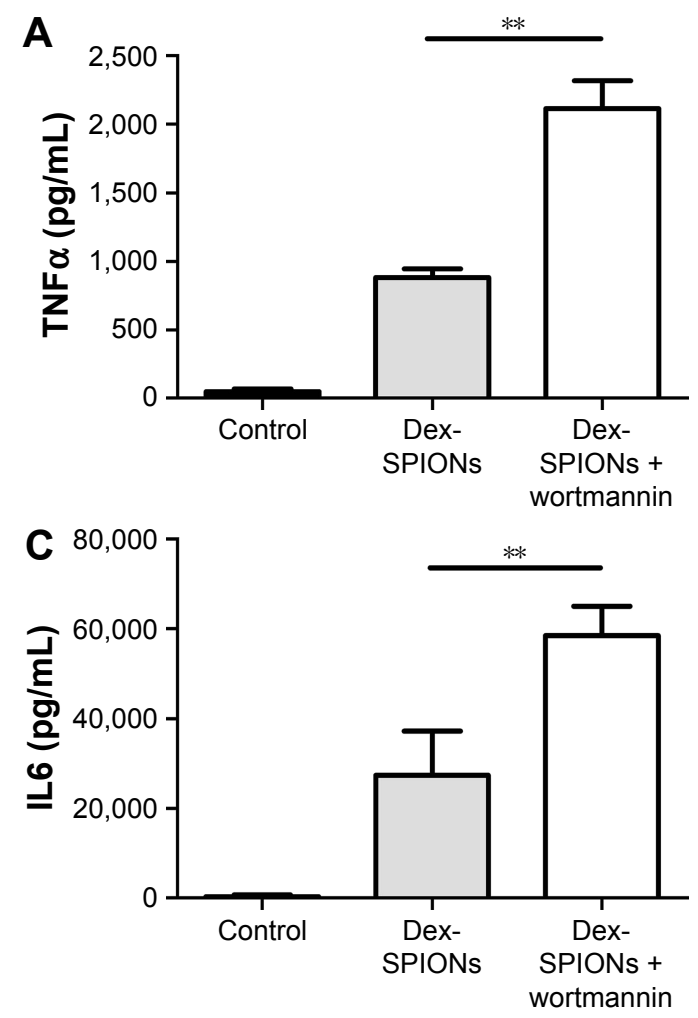

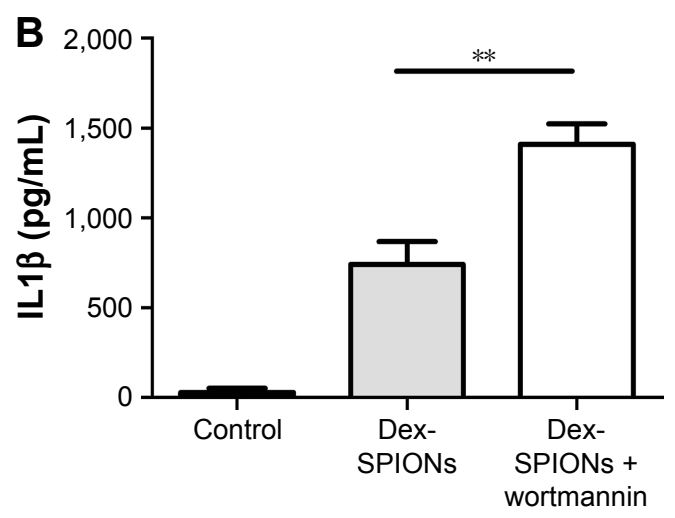

D

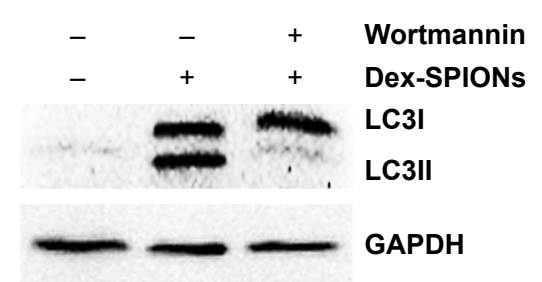

Figure 7 Inhibition of autophagy enhanced inflammation of human monocytes.

Notes: $* * P<0.01 ; n=3$. Cells were treated with Dex-SPIONs $(100 \mu g / m L)$ for 24 hours. Wortmannin $(50 \mathrm{nM})$ was added to the cells for 2 hours prior to Dex-SPION treatment. (A) TNF $\alpha$ levels; (B) ILI $\beta$ levels; (C) IL6 levels. (D) LC3 measured at 24 hours.

Abbreviation: Dex-SPIONs, dextran coated superparamagnetic iron oxide nanoparticles. 


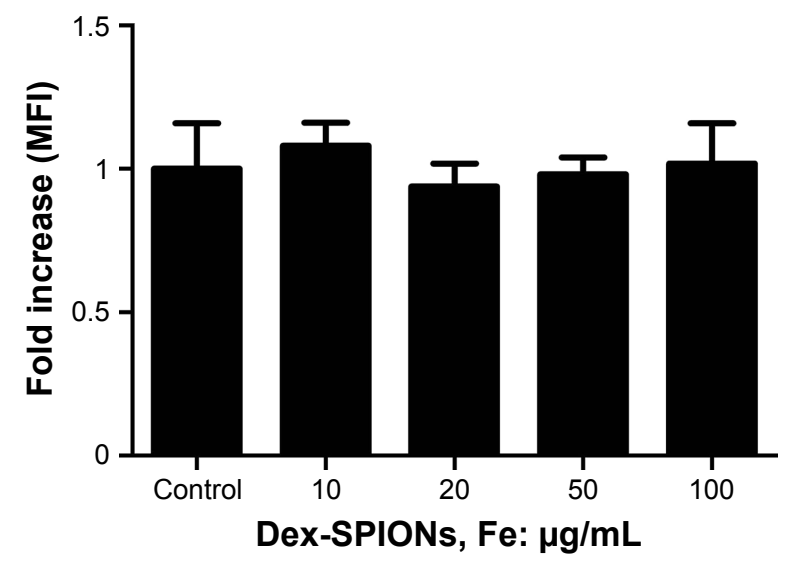

Figure 8 Effect of Dex-SPIONs on phagocytosis of human monocytes. Notes: Human monocytes were treated with Dex-SPIONs $(10-100 \mu \mathrm{g} / \mathrm{mL})$ for 24 hours. Immediately, the MFI of cells was measured by Multiskan Spectrum $(n=3)$. Abbreviations: Dex-SPIONs, dextran coated superparamagnetic iron oxide nanoparticles; MFI, mean fluorescence intensity.

on phagocytosis of cells was inspected by Multiskan Spectrum monitoring of the ingestion of fluorescent $E$. coli bacteria opsonized with an anti-E. coli antibody. As shown in Figure 8, we found that incubation of Dex-SPIONs at $10-100 \mu \mathrm{g} / \mathrm{mL}$ for 24 hours did not significantly affect phagocytosis of human monocytes.

\section{Discussion}

SPIONs have broad biomedical applications, and their biosafety is of great interest. Most current studies discuss the potential toxicity of SPIONs in nonhuman cells or immortalized cell lines. In this study, we evaluated the safety of Dex-SPIONs in human monocytes.

The accumulation of IONs and release of free iron from SPIONs might impair iron homeostasis in cells, resulting in inflammation, DNA damage, or other cytotoxic effects. ${ }^{27,28}$ The cytotoxicity of SPIONs is debatable. For instance, no cytotoxicity was observed when a murine macrophage cell line was treated with carboxydextran-coated SPIONs or uncoated SPIONs. ${ }^{29}$ It has been reported that Dex-stabilized SPIONs (Ferumoxides; Endorem, Sulzbach, Germany) might virtually change endothelial integrity and function. ${ }^{30}$ This might depend on NP size, modifications, or cell types studied. Coating is vital to stabilize SPIONs, because it can decrease the toxicity of SPIONs by preventing agglomeration and leakage of free iron ions. Dex has excellent biocompatibility, and has been used in clinics for a long time, but modification of cell-cell interaction and cell viability has also been observed. ${ }^{31}$ However, our data found no impact on viability and autophagy of cells by Dex. These results indicated that these NPs had good biocompatibility.
Moreover, we found that Dex-SPIONs entered human monocytes in a dose-dependent manner and did not affect phagocytosis behavior, similar to the findings by Müller et al. ${ }^{32}$ In that study, they showed that ferumoxtran-10, a dextran-coated SPION, had no influence on phagocytosis to human monocyte macrophages for 4 hours at various concentrations $(100-1,000 \mu \mathrm{g} / \mathrm{mL})$ and even 4 days at $400 \mu \mathrm{g} / \mathrm{mL}$. Cytokines, particularly proinflammatory cytokines, are useful tools in evaluating NP immunotoxicity. ${ }^{33}$ In the present study, we detected that proinflammatory cytokines (TNF $\alpha$, IL1 $\beta$, or IL6) increased after Dex-SPION exposure (Figure 6). It was possible that Dex-SPIONs induced immunotoxicity in human monocytes by accelerating the inflammation. At present, autophagy has been reported as the pivotal mechanism of NP toxicity. ${ }^{34}$ It is surmised that NP-induced autophagy may be an accommodative cellular response, assisting in the degradation and clearance of NPs. ${ }^{35}$

Several studies have reported that autophagy can be induced by IONs in different cell lines, ${ }^{36,37}$ but no information is available on autophagy induced by Dex-SPIONs in human primary cells. Ultrastructural detection has been considered the golden standard of autophagy. In Figure $2 \mathrm{C}$ and D, we show an autophagic reaction by TEM, and the enhanced LC3II expression and punctate structure further verified autophagosome accumulation in treated cells (Figure 3). It is well accepted that autophagosome accumulation can be induced by either induction of autophagy or blockade of autophagy flux. Nevertheless, the possibility of the latter has rarely been investigated. In our study, we found that DexSPIONs induced autophagy but did not block autophagy flux. As the autophagic substrate, p62 is selectively degraded by autophagy. ${ }^{23}$ Recent studies have indicated that cells can select NPs for autophagy by ubiquitination directly or indirect colocalization with ubiquitinated protein aggregates. ${ }^{38-40}$

First, we found that Dex-SPIONs located in autophagosomes with some organelles, and then p62 degraded in a dose-dependent manner (Figure 4A). It is possible that Dex-SPIONs undergo ubiquitination or colocalize with polyubiquitin complexes, and then are targeted to autophagosomes by p62. We surmised that PI3K signaling might be involved in Dex-SPION-mediated autophagy. Recently, Duan et al reported that silica NPs induced autophagic activity by the VEGFR2-PI3K-Akt-mTOR mediated autophagy pathway in endothelial cells, which plays a key role in maintaining vascular and endothelium homeostasis. ${ }^{41}$ It is well documented that many NPs can induce autophagy dysfunction and this may contribute to the toxicity of NPs. ${ }^{34}$ 
However, the interaction between autophagy (rather than autophagy dysfunction induced by NPs) and cell function is rarely addressed, such as in inflammation. It is noteworthy that there is cross talk between cytokines and autophagy in regard to the inflammatory response. ${ }^{42}$ Cytokines can induce autophagic activity, and autophagy can also adjust the production of inflammatory cytokines. ${ }^{42}$ In our study, we proposed that autophagy can adjust the production of proinflammatory factors and play a protection role in resisting the inflammation induced by Dex-SPIONs. However, whether the Dex-SPION-induced autophagy was primarily caused by these cytokines needs further investigation. In addition, autophagy is considered to have dual effects on cell viability. Initially, it was considered protective against cell death and during nutrient deficiency, but later studies revealed that a boost in autophagy might cause cell death. ${ }^{8,43}$ In respect to the autophagy induced by NPs, most of which can promote cell death. ${ }^{44,45}$ This phenomenon has resulted in the viewpoint that the autophagy induced by NPs is essentially detrimental to cells, because NPs are likely to be incorporated into the autophagosomes during autophagy but cannot be degraded through the lysosomal pathway, which may disturb the normal autophagic process.

In this study, however, we found that autophagy played a prosurvival instead of a cell-death role. The uptake of iron content by human monocytes was relatively low (5 pg/cell), and previous studies have demonstrated that Dex-SPIONs are metabolized in the lysosomes and then became a part of the body normal blood pool. ${ }^{46}$ Interestingly, we found that DexSPIONs increased the viability of monocytes after a longer period. Circulation monocytes are difficult to survive without differentiation in vitro, as they can have apoptosis and cell dealth. ${ }^{47}$ Autophagy is necessary for the process of differentiation of monocytes and macrophages, and is key for their survival and differentiation. ${ }^{48}$ The mechanism by which Dex-SPIONs increased the survival of monocytes is not clear, but one possible explanation may be inducing autophagy to promote differentiation of monocytes and then preventing apoptosis.

Our study suggested that there exists cross talk in these different effects induced by Dex-SPIONs in human monocytes. Contrary to cell dysfunction, autophagic activation may be a pivotal player against NP toxicity in human monocytes. Overall, this study offers a different perspective in understanding SPION safety and NP-induced cell behaviors.

\section{Conclusion}

In this study, we evaluated the effects of Dex-SPIONs on human monocyte cells. Our data demonstrated that
Dex-SPIONs induced autophagy but did not block autophagy flux in human monocytes. During NP-cell interactions, increased expression of LC3II and degradation of $\mathrm{p} 62$ protein was observed, with elevated proinflammatory cytokines. Moreover, inhibition of autophagy almost attenuated the survival of cells, whereas it accelerated the inflammation induced by Dex-SPIONs. These results indicate that the induction of autophagy by these NPs has an important role in the survival and function of human monocyte cells.

\section{Acknowledgments}

This work was financially supported by the National Key Basic Research Program of China (2013CB933903) and the National Natural Science Foundation of China (81471848).

\section{Disclosure}

The authors report no conflicts of interest in this work.

\section{References}

1. Shi M, Cheng L, Zhang Z, Liu Z, Mao X. Ferroferric oxide nanoparticles induce prosurvival autophagy in human blood cells by modulating the Beclin1/Bcl-2/VPS34 complex. Int J Nanomedicine. 2014;10:207-216.

2. Mahmoudi M, Hosseinkhani H, Hosseinkhani M, et al. Magnetic resonance imaging tracking of stem cells in vivo using iron oxide nanoparticles as a tool for the advancement of clinical regenerative medicine. Chem Rev. 2011;111(2):253-280.

3. Tran N, Webster TJ. Magnetic nanoparticles: biomedical applications and challenges. J Mater Chem. 2010;(40):8760-8767.

4. Sun C, Lee JS, Zhang M. Magnetic nanoparticles in MR imaging and drug delivery. Adv Drug Deliv Rev. 2008;60(11):1252-1265.

5. Wu X, Tan Y, Mao H, Zhang M. Toxic effects of iron oxide nanoparticles on human umbilical vein endothelial cells. Int J Nanomedicine. 2010;5:385-399.

6. Mizushima N, Levine B, Cuervo AM, Klionsky DJ. Autophagy fights disease through cellular self-digestion. Nature. 2008;451(7182): 1069-1075.

7. Mizushima N. Autophagy: process and function. Genes Dev. 2007; 21(22):2861-2873.

8. Shen HM, Codogno P. Autophagy is a survival force via suppression of necrotic cell death. Exp Cell Res. 2012;318(11):1304-1308.

9. Meléndez A, Tallóczy Z, Seaman M, Eskelinen EL, Hall DH, Levine B. Autophagy genes are essential for dauer development and life-span extension in C. elegans. Science. 2003;301(5638):1387-1391.

10. Zabirnyk O, Yezhelyev M, Seleverstov O. Nanoparticles as a novel class of autophagy activators. Autophagy. 2007;3(3):278-281.

11. Liu HL, Zhang YL, Yang N, et al. A functionalized single-walled carbon nanotube-induced autophagic cell death in human lung cells through Akt-TSC2-mTOR signaling. Cell Death Dis. 2011;2:e159.

12. Li C, Liu H, Sun Y, et al. PAMAM nanoparticles promote acute lung injury by inducing autophagic cell death through the Akt-TSC2-mTOR signaling pathway. J Mol Cell Biol. 2009;1(1):37-45.

13. Robbins CS, Swirski FK. The multiple roles of monocyte subsets in steady state and inflammation. Cell Mol Life Sci. 2010;67(16): 2685-2693.

14. Hong RY, Feng B, Chen LL, et al. Synthesis, characterization and MRI application of dextran-coated $\mathrm{Fe}_{3} \mathrm{O}_{4}$ magnetic nanoparticles. Biochem Eng J. 2008;42(3):290-300. 
15. Bachmann S, Schlichting U, Geist B, et al. Kidney-specific inactivation of the megalin gene impairs trafficking of renal inorganic sodium phosphate cotransporter (NaPi-lla). J Am Soc Nephrol. 2004;15(4): 892-900.

16. Fish WW. Rapid colorimetric micromethod for the quantitation of complexed iron in biological samples. Methods Enzymol. 1988;158: 357-364.

17. Tassa C, Shaw SY, Weissleder R. Dextran-coated iron nanoparticles: a versatile platform for targeted molecular imaging, molecular diagnostics, and therapy. Acc Chem Res. 2011;44(10):842-852.

18. Mizushima N, Yoshimori T. How to interpret LC3 immunoblotting. Autophagy. 2007;3(6):542-545.

19. Takahashi Y, Coppola D, Matsushita N, et al. Bif-1 interacts with Beclin1 through UVRAG and regulates autophagy and tumorigenesis. Nat Cell Biol. 2007;9(10):1142-1151.

20. Kabeya Y, Mizushima N, Ueno T, et al. LC3, a mammalian homologue of yeast Apg8p, is localized in autophagosome membranes after processing. EMBO J. 2000;19(21):5720-5728.

21. Klionsky DJ, Abdelmohsen K, Abe A, et al. Guidelines for the use and interpretation of assays for monitoring autophagy (3rd edition). Autophagy. 2016;12(1):1-222.

22. Mizushima N, Yoshimori T, Levine B. Methods in mammalian autophagy research. Cell. 2010;140(3):313-326.

23. Bjørkøy G, Lamark T, Brech A, et al. p62/SQS TM1 forms protein aggregates degraded by autophagy and has a protective effect on huntingtininduced cell death. J Cell Biol. 2005;171(4):603-614.

24. Blommaart EF, Krause U, Schellens JP, Vreeling-Sindelárová H, Meijer AJ. The phosphatidylinositol 3-kinase inhibitors wortmannin and LY294002 inhibit autophagy in isolated rat hepatocytes. Eur $J$ Biochem. 1997;243(1-2):240-246.

25. Cao B, Li J, Zhou X, et al. Clioquinol induces pro-death autophagy in leukemia and myeloma cells by disrupting the mTOR signaling pathway. Sci Rep. 2014;4:5749.

26. Hussain S, Al-Nsour F, Rice AB, et al. Cerium dioxide nanoparticles induce apoptosis and autophagy in human peripheral blood monocytes. ACS Nano. 2012;6(7):5820-5829.

27. Murray AR, Kisin E, Inman A, et al. Oxidative stress and dermal toxicity of iron oxide nanoparticles in vitro. Cell Biochem Biophys. 2013; 67(2):461-476.

28. Srinivas A, Rao PJ, Selvam G, Goparaju A, Murthy PB, Raddy PN. Oxidative stress and inflammatory responses of rat following acute inhalation exposure to iron oxide nanoparticles. Hum Exp Toxicol. 2012; 31(11):1113-1131.

29. Hsiao JK, Chu HH, Wang YH, et al. Macrophage physiological function after superparamagnetic iron oxide labeling. NMR Biomed. 2008;21(8):820-829.

30. Astanina K, Simon Y, Cavelius C, Petry S, Kraegeloh A, Kiemer AK. Superparamagnetic iron oxide nanoparticles impair endothelial integrity and inhibit nitric oxide production. Acta Biomater. 2014;10(11): 4896-4911.

31. Rouleau L, Rossi J, Leask RL. Concentration and time effects of dextran exposure on endothelial cell viability, attachment, and inflammatory marker expression in vitro. Ann Biomed Eng. 2010;38(4):1451-1462.
32. Müller K, Skepper JN, Posfai M, et al. Effect of ultrasmall superparamagnetic iron oxide nanoparticles (ferumoxtran-10) on human monocyte-macrophages in vitro. Biomaterials. 2007;28(9):1629-1642.

33. Elsabahy M, Wooley KL. Cytokine as biomarkers of nanoparticle immunotoxicity. Chem Soc Rev. 2013;42(12):5552-5576.

34. Stern ST, Adiseshaiah PP, Crist RM. Autophagy and lysosomal dysfunction as emerging mechanisms of nanomaterial toxicity. Part Fibre Toxicol. 2012;9:20.

35. Zhou W, Miao Y, Zhang Y, et al. Induction of cyto-protective autophagy by paramontroseite $\mathrm{VO}_{2}$ nanocrystals. Nanotechnology. 2013;24(16): 165102 .

36. Khan MI, Mohammad A, Patil G, Naqvi SA, Chauhan LK, Ahmad I. Induction of ROS, mitochondrial damage and autophagy in lung epithelial cancer cells by iron oxide nanoparticles. Biomaterials. 2012 33(5):1477-1488.

37. Halamoda Kenzaoui B, Chapuis Bernasconi C, Guney-Ayra S, JuilleratJeanneret L. Induction of oxidative stress, lysosome activation and autophagy by nanoparticles in human brain-derived endothelial cells. Biochem J. 2012;441(3):813-821.

38. Chen M, Von Mikecz A. Formation of nucleoplasmic protein aggregates impairs nuclear function in response to $\mathrm{SiO}_{2}$ nanoparticles. Exp Cell Res. 2005;305(1):51-62.

39. Zheng YT, Shahnazari S, Brech A, Lamark T, Johansen T, Brumell JH. The adaptor protein p62/SQSTM1 targets invading bacteria to the autophagy pathway. J Immunol. 2009;183(9):5909-5916.

40. Calzolai L, Franchini F, Gilliland D, Rossi F. Protein-nanoparticle interaction: identification of the ubiquitin-gold nanoparticle interaction site. Nano Lett. 2010;10(8):3101-3105.

41. Duan J, Yu Y, Yu Y, et al. Silica nanoparticles enhance autophagic activity, disturb endothelial cell homeostasis and impair angiogenesis. Part Fibre Toxicol. 2014;11:50.

42. Harris J. Autophagy and cytokines. Cytokine. 2011;56(2):140-144.

43. Maiuri MC, Zalckvar E, Kimchi A, Kroemer G. Self-eating and selfkilling: crosstalk autophagy and apoptosis. Nat Rev Mol Cell Biol. 2007; 8(9):741-752.

44. Zhang Q, Yang W, Man N, et al. Autophagy-mediated chemosensitization in cancer cells by fullerene C60 nanocrystal. Autophagy. 2009; 5(8):1107-1117.

45. Yu L, Lu Y, Man N, Yu SH, Wen LP. Rare earth oxide nanocrystals induce autophagy in HeLa cells. Small. 2009;5(24):2784-2787.

46. Lunov O, Zablotskii V, Syrovets T, et al. Modeling receptor-mediated endocytosis of polymer-functionalized iron oxide nanoparticles by human macrophages. Biomaterials. 2011;32(2):547-555.

47. Ricardo SD, Van Goor H, Eddy AA. Macrophage diversity in renal injury and repair. J Clin Invest. 2008;118(11):3522-3530.

48. Zhang Y, Morgan MJ, Chen K, Choksi S, Liu ZG. Induction of autophagy is essential for monocyte-macrophage differentiation. Blood. 2012;119(12):2895-2905.
International Journal of Nanomedicine

\section{Publish your work in this journal}

The International Journal of Nanomedicine is an international, peerreviewed journal focusing on the application of nanotechnology in diagnostics, therapeutics, and drug delivery systems throughou the biomedical field. This journal is indexed on PubMed Central, MedLine, CAS, SciSearch $®$, Current Contents $\AA /$ Clinical Medicine,

\section{Dovepress}

Journal Citation Reports/Science Edition, EMBase, Scopus and the Elsevier Bibliographic databases. The manuscript management system is completely online and includes a very quick and fair peer-review system, which is all easy to use. Visit http://www.dovepress.com/ testimonials.php to read real quotes from published authors. 